\title{
A Metabolically Unhealthy Phenotype Is Associated with ADIPOQ Genetic Variants and Lower Serum Adiponectin Levels
}

\author{
Nathaly Torres-Castillo Wendy Campos-Perez Roberto Rodriguez-Echevarria \\ Sarai Citlalic Rodriguez-Reyes Erika Martinez-Lopez \\ Institute of Translational Nutrigenetics and Nutrigenomics, Department of Molecular Biology and Genomics, \\ University Center of Health Sciences, University of Guadalajara, Guadalajara, Mexico
}

\section{Keywords}

Metabolically unhealthy phenotype - Adiponectin - Obesity · Genetic variants

\begin{abstract}
Background: Even though excessive adipose tissue is related to chronic metabolic disturbances, not all subjects with excess weight (EW) display metabolic alterations, and not all normal-weight (NW) subjects have a metabolically healthy $(\mathrm{MH})$ phenotype, probably due to gene-environment interactions. The aim of this study was to investigate the interaction effects of $A D I P O Q$ and PPARG genetic variants in NW and EW individuals with different metabolic phenotypes. Methods: Data on 345 adults from western Mexico were analyzed. The individuals were classified into NW and EW groups according to body mass index, and were categorized as $\mathrm{MH}$ or metabolically unhealthy (MUH), considering homeostatic model assessment insulin resistance (HOMA-IR) and National Cholesterol Education Program Adult Treatment Panel III (NCEP-ATP III) cut-off points for glucose, triglycerides, highdensity lipoprotein cholesterol, and blood pressure. Subjects with $\leq 1$ altered parameter were classified as $\mathrm{MH}$. The single nucleotide polymorphisms (SNPs) $-11377 \mathrm{C}>\mathrm{G}$, $-11391 \mathrm{G}>\mathrm{A},+45 \mathrm{~T}>\mathrm{G}$, and +276G $>\mathrm{T}$ for ADIPOQ and Pro-
\end{abstract}

karger@karger.com

Karger $\frac{1}{\%}$

GOPEN ACCESS www.karger.com/lfg
(C) 2020 The Author(s)

Published by S. Karger AG, Basel

This article is licensed under the Creative Commons AttributionNonCommercial-NoDerivatives 4.0 International License (CC BYNC-ND) (http://www.karger.com/Services/OpenAccessLicense). Usage and distribution for commercial purposes as well as any distribution of modified material requires written permission.
12Ala for PPARG were analyzed by allelic discrimination. High-molecular-weight adiponectin isoform levels were measured by ELISA. Results: Lower serum adiponectin levels were associated with the MUH phenotype in EW subjects. NW subjects with the GG or TG genotype for the +45T>G SNP had reduced odds of the MUH phenotype. Individuals who carried two copies of the GG haplotype at the $-11391 \mathrm{G}>\mathrm{A}$ and -11377 C $>$ G SNPs for ADIPOQ had lower serum adiponectin levels than those with zero copies. Conclusion: In this population, lower serum adiponectin levels were found in the EW-MUH phenotype, and no differences were observed between the NW-MH and the EW-MH phenotype. In addition, the $+45 T>G$ SNP was associated with reduced odds of the MUH phenotype.

(C) 2020 The Author(s)

Published by S. Karger AG, Basel

\section{Introduction}

Adipose tissue has long been acknowledged as an endocrine organ that plays an important role in overall metabolic homeostasis [1,2]. An excessive adipose mass has been described as the main cause of metabolic distur-

\section{N.T.-C. and W.C.-P. contributed equally to this work.}


Fig. 1. Possible mechanisms of interaction in development of the MUH phenotype. The MUH phenotype is presented in NW and EW subjects. Subjects with NW could have dysfunctional adipose tissue similar to EW subjects, which leads to the MUH phenotype. In addition, in subjects with EW, the excess of adipose tissue also favors more adipose tissue dysfunction. These factors - accompanied by some genetic polymorphisms in genes implicated in adiponectin and lipid metabolism, such as $A D I P O Q$ and PPARG - could result in lower expression and concentrations of HMW adiponectin, dyslipidemia, and lower insulin sensitivity, ensuring the development of the MUH phenotype. NW, normal weight; EW, excess weight; SNP, single nucleotide polymorphism; HMW, high molecular weight; MUH, metabolically unhealthy.

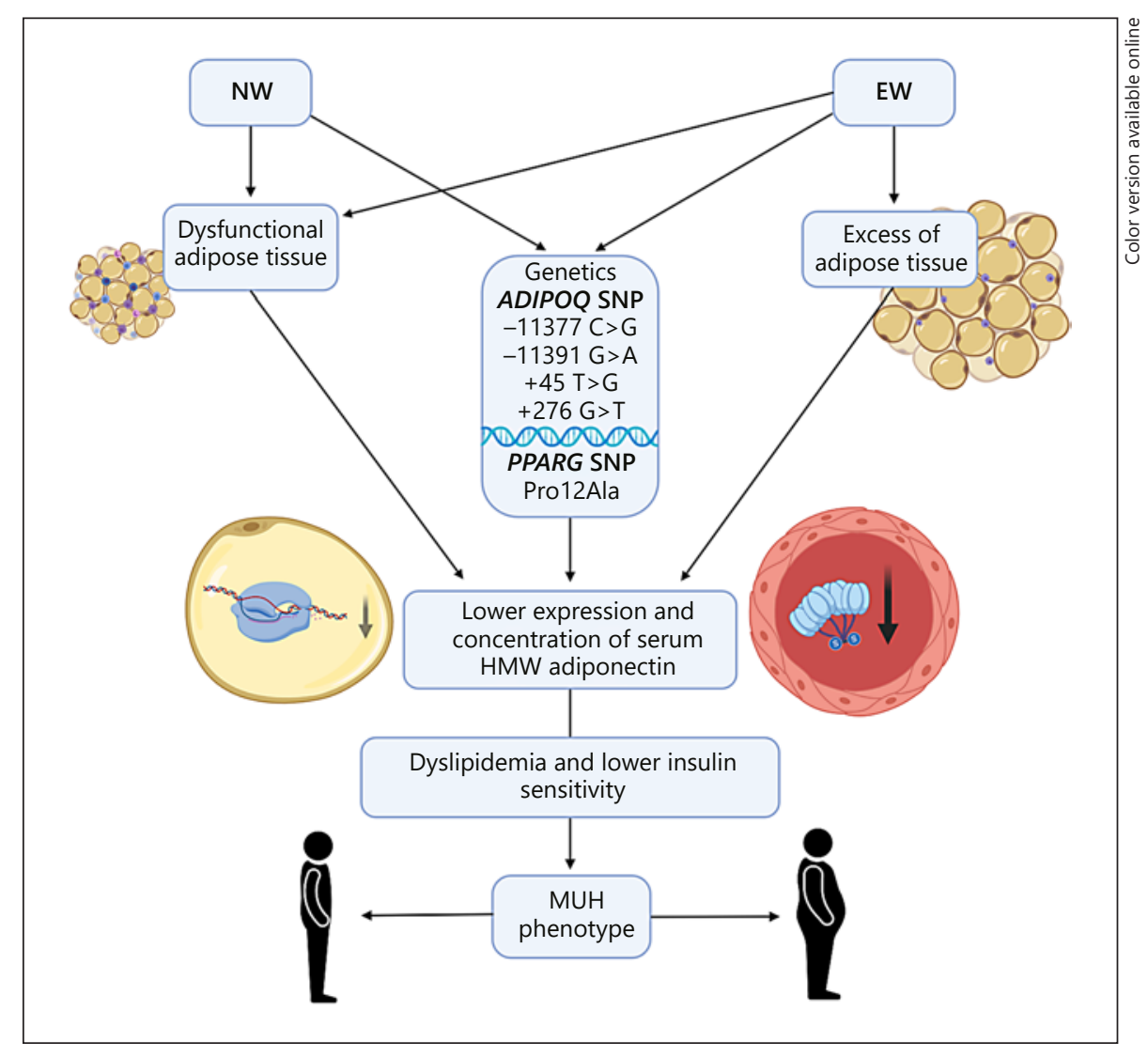

bances due to a switch in the secretion of proinflammatory adipokines/cytokines (TNF- $\alpha$ and IL-6) versus adiponectin $[3,4]$. The latter is responsible for the regulation of energy expenditure and lipid catabolism, as well as for enhancing fatty acid oxidation and insulin sensitivity [5].

However, not only an excessive amount of adipose tissue is involved in such alterations: dysfunctional adipose tissue (in both normal-weight [NW] and obese individuals), macrophage infiltration [6], fat distribution [7], and hypertrophic adipocytes [8] are also involved in the development of metabolic complications [9]. In this regard, the body mass index (BMI) is still used as a tool for categorizing subjects as NW, overweight, or obese, though it does not provide data on fat content or distribution [10].

Over two-thirds of Mexico's population are either overweight or obese. Thus, it would be expected that there is a similar prevalence of dyslipidemias, insulin resistance, and other metabolic alterations usually seen in people with obesity. However, not all subjects with overweight or obesity present these metabolic complications
(Fig. 1) [11]. This fact allows further individual classification based on the phenotype, that is, metabolically healthy $(\mathrm{MH})$ and metabolically unhealthy $(\mathrm{MUH})$, which may apply to NW or excess-weight (EW) individuals. The specific criteria for this classification comprise systemic blood pressure, the lipid profile, fasting blood glucose, and homeostatic model assessment insulin resistance (HOMA-IR). Nevertheless, it is important to mention that although these criteria have been used and adapted by various authors $[11,12]$, they have not yet been standardized.

In addition, some reports have found a strong association between low systemic adiponectin levels and a higher cardiometabolic risk in obese individuals [13]. Nonetheless, the underlying mechanism for altered adiponectin expression and secretion has yet to be elucidated, even though it has been reported that excess adipose tissue [14] and its dysfunction could be implicated (Fig. 1) [15]. Moreover, some genetic adiponectin variants have been in the spotlight, such as $-11377 \mathrm{C}>\mathrm{G}$ (rs266729), $-11391 \mathrm{G}>\mathrm{A}$ (rs17300539), $+45 \mathrm{~T}>\mathrm{G}$ (rs2241766), and $+276 \mathrm{G}>\mathrm{T}$ (rs1501299). These single nucleotide polymor- 
phisms (SNPs) have been associated with hypoadiponectinemia, insulin resistance, and type 2 diabetes mellitus (T2D) [4, 16-18]. Furthermore, PPARG Pro12Ala (rs1801282), which is another relevant SNP, has been considered as a contributor to traits of metabolic alteration. In fact, it encodes a transcriptional factor (PPAR- $\gamma$ ) involved in the regulation of lipid metabolism and insulin sensitivity due to its crucial role in upregulation of the adiponectin gene [16, 19-22].

Thus, we hypothesize that these ADIPOQ and PPARG genetic variants are associated with adiponectin serum levels and the $\mathrm{MH}$ and MUH phenotypes.

\section{Subjects and Methods}

\section{Study Subjects}

In this cross-sectional study, a total of 345 unrelated adults from western Mexico were recruited from 2011 to 2012 in the Medical Molecular Biology Service at "Fray Antonio Alcalde" Civil Hospital of Guadalajara. The previous clinical history of the study subjects was assessed. Included were Mestizos from western Mexico, aged 18-65 years, with the following BMI classifications: NW (18.5-24.9 kg/m²), overweight (25-29.9 kg/m²), and obese $\left(\geq 30 \mathrm{~kg} / \mathrm{m}^{2}\right)$. The exclusion criteria were: pharmacological treatment for chronic pathological conditions such as T2D and cardiovascular, liver, kidney or pancreatic diseases; having any type of drug addiction; increased alcohol consumption (alcohol intake $>20$ and $>40 \mathrm{~g} /$ day for women and men, respectively); and being pregnant or breastfeeding. The study was approved by the Ethics Committee for Human Research of the University of Guadalajara (registration No. CI/019/2010) and conducted according to the Declaration of Helsinki [23].

\section{Definition of the MH and MUH Phenotypes}

It is important to point out that there is no consensus definition of the $\mathrm{MH}$ phenotype; however, as other authors [24-26], we used some of the cut-off points for the metabolic syndrome by the National Cholesterol Education Program Adult Treatment Panel III (NCEP-ATP III) [27] as follows: blood pressure $\geq 130 / 85 \mathrm{~mm} \mathrm{Hg}$, triglycerides $\geq 150 \mathrm{mg} / \mathrm{dL}$, HDL (high-density lipoprotein) cholesterol $<40 \mathrm{mg} / \mathrm{dL}$ in men and $<50 \mathrm{mg} / \mathrm{dL}$ in women, fasting blood glucose $\geq 100 \mathrm{mg} / \mathrm{dL}$, and HOMA-IR $>2.5$ [28]. If subjects had one or none of these altered values, they were considered as $\mathrm{MH}$; otherwise, they were classified as MUH. Subjects with a BMI between 18.5 and $24.9 \mathrm{~kg} / \mathrm{m}^{2}$ were defined as NW and those with a BMI $\geq 25$ $\mathrm{kg} / \mathrm{m}^{2}$ were defined as EW. Hence, four groups were studied: NW$\mathrm{MH}, \mathrm{NW}-\mathrm{MUH}, \mathrm{EW}-\mathrm{MH}$, and EW-MUH.

\section{Anthropometric and Clinical Measurements}

Anthropometric parameters were measured after $12 \mathrm{~h}$ of fasting with a disposable gown and without shoes. Measurements of height, weight, body fat percentage (InBody 3.0; Biospace Co., Seoul, South Korea), BMI, and blood pressure were obtained as previously described [12].

\section{Biochemical Analysis}

Blood samples were taken in the morning, after a period of $12-\mathrm{h}$ fasting, by venous puncture. Immediately, serum was separated and stored at $-80^{\circ} \mathrm{C}$. Triglycerides, HDL cholesterol, and fasting glucose were determined by dry chemistry (Vitros 250 Analyzer; Ortho Clinical Diagnostics, Johnson \& Johnson, Co., Rochester, NY, USA). Insulin determination was performed by ELISA (Monobind Inc., Lake Forest, CA, USA). HOMA-IR was calculated according to the Matthews formula [28].

High-molecular-weight (HMW) adiponectin isoform levels were measured by ELISA according to the manufacturer's recommendations (ALPCO Diagnostics, Salem, NH, USA). Hypoadiponectinemia was defined as adiponectin levels $<3 \mu \mathrm{g} / \mathrm{mL}$ [29].

\section{DNA Extraction and Genotyping}

For the extraction of genomic DNA, the modified Miller technique was used [30]. Genotyping for the ADIPOQ $-11391 \mathrm{G}>\mathrm{A}$, $-11377 \mathrm{C}>\mathrm{G},+45 \mathrm{~T}>\mathrm{G}$, and $+276 \mathrm{G}>\mathrm{T}$ and the PPARG Pro12Ala polymorphisms was performed using the TaqMan ${ }^{\circledR}$ allelic discrimination assay in a real-time PCR (polymerase chain reaction) system. The amplification reaction was carried out in a LightCycler $^{\circledR} 96$ Real-Time PCR System (Roche Diagnostics, Mannheim, Germany) with the following conditions: a pre-incubation stage at $95^{\circ} \mathrm{C}$ for $600 \mathrm{~s}$, then 40 cycles of $15 \mathrm{~s}$ each at $95^{\circ} \mathrm{C}$, and $60 \mathrm{~s}$ at $60^{\circ} \mathrm{C}$. A mixture was prepared for the reaction with FastStart TaqMan ${ }^{\circledR}$ probe master $2 \times$, SNP $20 \times$, and genomic DNA (20 ng/ $\mu \mathrm{L})$. Duplicated analyses were performed on $20 \%$ of the samples to avoid genotyping errors.

\section{Statistical Analysis}

The sample size was calculated to detect a minimal difference of $1.97 \mu \mathrm{g} / \mathrm{mL}$ of HMW adiponectin between the EW-MH and the EW-MUH phenotype [31] with a statistical power of $80 \%$ and a level of confidence of $95 \%$. Because previous studies did not report HMW adiponectin comparing NW-MH versus NW$\mathrm{MUH}$ versus EW-MH versus EW-MUH, these comparisons were exploratory.

The Kolmogorov-Smirnov test was used to evaluate the normal distribution of quantitative variables, and those with nonnormal distribution were log-transformed and then the normality test was performed to verify their normal distribution. To analyze differences between the four phenotypes, one-way ANOVA was performed. The $\chi^{2}$ test was used to compare categorical variables and to calculate the Hardy-Weinberg equilibrium.

The ANCOVA test was used to compare adiponectin concentrations between phenotypes and genotypes, and because its amount is influenced by sex and age, these two variables were defined as covariates using Bonferroni post hoc correction for multiple comparisons. When adiponectin was assessed in the entire population, BMI was added as a covariate.

The association analyses of the polymorphisms and phenotypes were performed with binary logistic regression, adjusted for sex, age, and hypoadiponectinemia. To estimate haplotype frequency, the EM algorithm for haplotype inference with multiallelic markers was used. The normalized linkage disequilibrium $\left(\mathrm{D}^{\prime}\right)$ and squared correlation of allele frequencies $\left(r^{2}\right)$ were estimated using the SHEsis online software (http://analysis.bio-x.cn). All other statistical analyses were performed using SPSS version 20.0 software (IBM Corp., Armonk, NY, USA). A $p$ value $<0.05$ was considered statistically significant. 
Table 1. Sociodemographic, anthropometric, and adiponectin variables in $\mathrm{MH}$ and MUH subjects

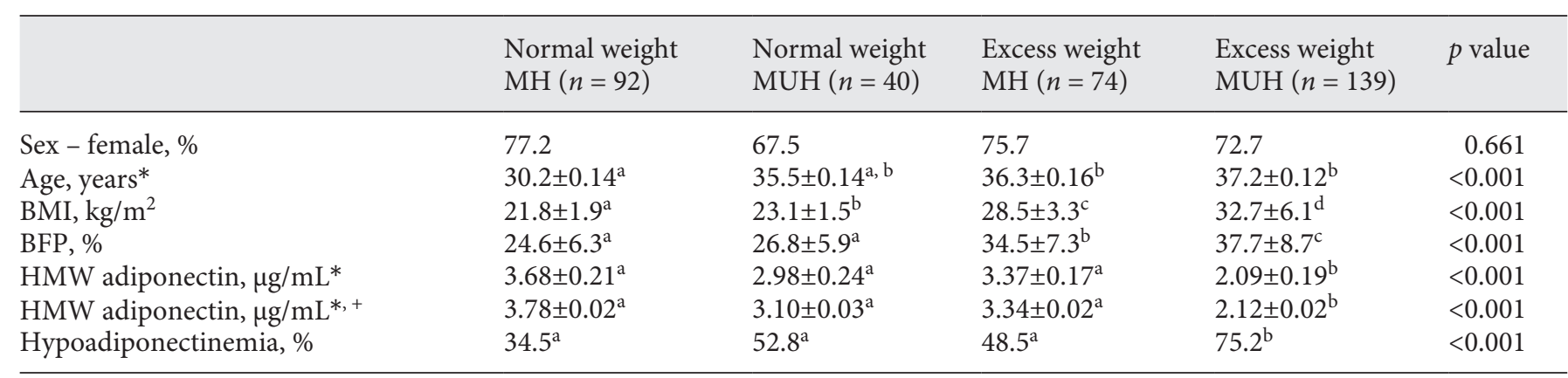

Data are expressed as mean \pm SD or percentage according to quantitative and qualitative variables. Means and proportions with different superscript letters are statistically different. $\mathrm{MH}$, metabolically healthy; $\mathrm{MUH}$, metabolically unhealthy; $\mathrm{BFP}$, body fat percentage; HMW, high molecular weight. * log-transformed for the analysis and then retransformed. ${ }^{+}$ANCOVA with sex and age as covariates and using the Bonferroni test for multiple comparisons.

Fig. 2. Linkage disequilibrium plots for the ADIPOQ polymorphisms in metabolically healthy (a) and metabolically unhealthy (b) subjects.

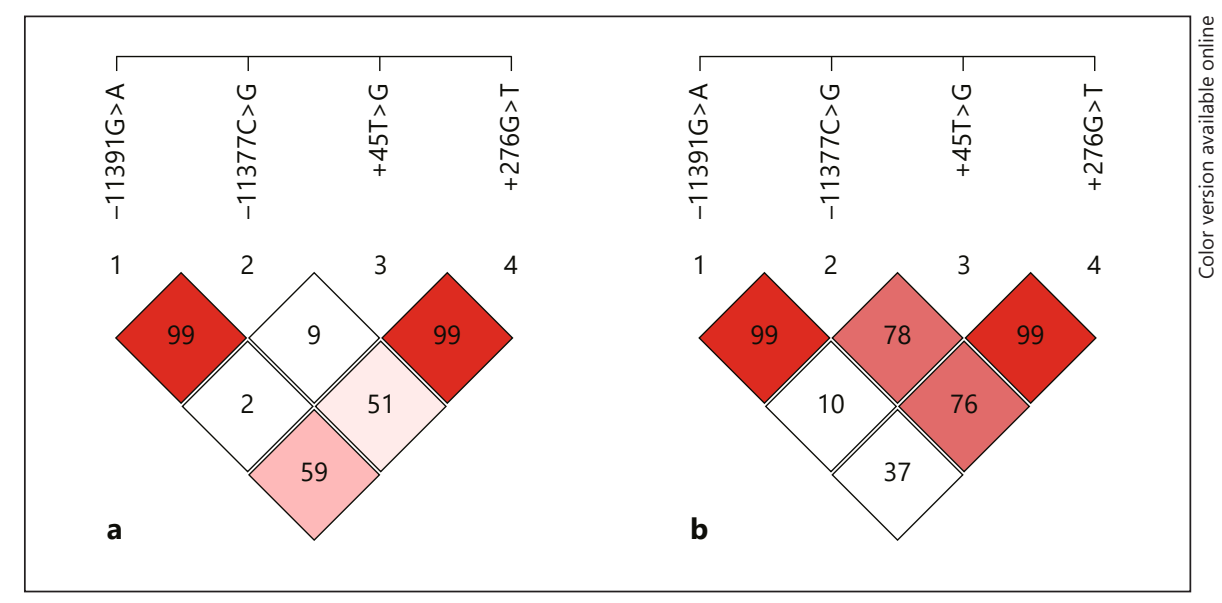

\section{Results}

\section{Characteristics of the Study Population}

In this study, 345 subjects were included, of whom $73.9 \%$ were women. The mean age was $36.8 \pm 11.7$ years. Among the subjects with NW, $69.7 \%$ had the MH phenotype, whereas among the subjects with EW, only $34.7 \%$ presented this phenotype. Age, BMI, body fat percentage, HMW adiponectin, and the percentage of individuals with hypoadiponectinemia were different between the metabolic phenotype groups (Table 1). HMW adiponectin levels remained different between the EW-MUH group and the other three groups even after adjustment for age and sex. Interestingly, no differences were found between NW-MH and EW-MH adiponectin concentrations (Table 1).
Genetic Characteristics of the Study Population

The genotype and allelicfrequencies of the $-11391 \mathrm{G}>\mathrm{A}$, $-11377 \mathrm{C}>\mathrm{G},+45 \mathrm{~T}>\mathrm{G}$, and $+276 \mathrm{G}>\mathrm{T}$ polymorphisms of $A D I P O Q$ and the Pro12Ala polymorphism of PPARG were compared between the $\mathrm{MH}$ and $\mathrm{MUH}$ phenotype groups with NW and EW; nevertheless, none of them showed any significant differences. All genotype frequencies were in Hardy-Weinberg equilibrium (online suppl. Table S1; see www.karger.com/doi/10.1159/000510021 for all online suppl. material).

The linkage disequilibrium plots of the four $A D I P O Q$ polymorphisms are shown in Figure 2 for both the $\mathrm{MH}$ (Fig. 2a) and MUH (Fig. 2b) phenotype groups. This analysis demonstrated the presence of two haplotype blocks. The first block consisted of $-11391 \mathrm{G}>\mathrm{A}$ and $-11377 \mathrm{C}>\mathrm{G}$ polymorphisms, and the second block of $+45 \mathrm{~T}>\mathrm{G}$ and $+276 \mathrm{G}>\mathrm{T}$ loci in the $\mathrm{MH}\left(\mathrm{D}^{\prime}=0.99, r^{2}=0.03\right.$ for the first block; $\mathrm{D}^{\prime}=0.99, r^{2}=0.07$ for the second block) and MUH 
$\left(\mathrm{D}^{\prime}=0.99, r^{2}=0.04\right.$ for the first block; $\mathrm{D}^{\prime}=0.99, r^{2}=0.06$ for the second block) phenotype groups. Thereafter, haplotype frequencies were compared between the $\mathrm{MH}$ and MUH phenotypes in the NW and EW groups, but no significant differences were observed (online suppl. Table S2).

\section{Association of SNPs and Haplotypes in ADIPOQ with} HMW Adiponectin Levels

The SNP $-11377 \mathrm{C}>\mathrm{G}$ of $A D I P O Q$ was associated with serum HMW adiponectin levels in the entire study population after adjustment for sex, age, and BMI (CC $3.13 \pm$ 0.02 vs. CG + GG $2.56 \pm 0.02 \mu \mathrm{g} / \mathrm{mL}, p=0.023)$; furthermore, subjects with two copies of the GG haplotype of the $-11391 \mathrm{G}>\mathrm{A}$ and $-11377 \mathrm{C}>\mathrm{G}$ polymorphisms had lower adiponectin levels than those with no copies $(2.29 \pm 0.03$ vs. $3.13 \pm 0.02 \mu \mathrm{g} / \mathrm{mL}, p=0.030)$. Other SNPs and haplotypes displayed no statistically significant differences (data not shown).

Association of ADIPOQ and PPARG Polymorphisms with Metabolic Phenotypes and Metabolic Traits

Out of the five polymorphisms studied in the ADIPOQ and $P P A R G$ genes and the haplotypes of the ADIPOQ gene that were analyzed for association with the metabolic phenotypes, only one polymorphism showed a significant association. It was observed that $\mathrm{NW}$ subjects with the GG or TG genotype of SNP $+45 \mathrm{~T}>\mathrm{G}$ displayed significantly lower odds of the MUH phenotype (Table 2 ). These five polymorphisms were also tested for associations with each of the five metabolic parameters used to define the $\mathrm{MH}$ and $\mathrm{MUH}$ phenotypes. Again, $+45 \mathrm{~T}>\mathrm{G}$ was the only polymorphism associated with hypertriglyceridemia when adjusted for age, sex, and BMI (OR 0.56, $95 \%$ CI 0.33-0.97, $p=0.039$ ).

\section{Discussion}

In spite of the fact that metabolic disorders result from the interaction between genetic and environmental factors, the former play an important role in the development of chronic diseases and the mortality rate worldwide $[32,33]$. However, it is not yet clear how ADIPOQ and $P P A R G$ genetic variants are associated with the $\mathrm{MH}$ and MUH phenotypes among subjects with either EW or NW.

In this study, we found that subjects with EW and the MUH phenotype have lower HMW adiponectin serum levels than $\mathrm{MH}$ subjects, which is congruent with other
Table 2. Association of an $A D I P O Q$ polymorphism with the metabolically unhealthy phenotype

\begin{tabular}{lllll}
\hline Polymorphism & \multicolumn{4}{l}{ Normal weight } \\
\cline { 2 - 5 } & $\mathrm{B}$ & p value & OR & $95 \% \mathrm{CI}$ \\
\hline$+45 \mathrm{~T}>\mathrm{G}$ ADIPOQ & -1.152 & 0.030 & 0.316 & $0.112-0.893$ \\
\hline
\end{tabular}

This model was adjusted for sex, age, and hypoadiponectinemia.

studies where lower adiponectin serum levels were found in subjects with unhealthy obesity. Moreover, adiponectin levels have been widely reported to be inversely associated with body fat. Interestingly, we found that subjects with EW and the $\mathrm{MH}$ phenotype did not present statistically significant differences regarding the levels of this adipokine compared to NW subjects with the MH phenotype, even though EW subjects have a higher body fat percentage. Other authors have reported similar findings in the Mexican population [26], but the mechanism explaining this fact has not yet been elucidated.

Regarding polymorphisms and the MUH phenotype, in one study, 503 Russian residents with abdominal obesity aged 30-55 years were classified as $\mathrm{MH}$ or MUH according to the International Diabetes Federation (based on the presence of central obesity even in the absence of insulin resistance, together with 2 or more components) and no statistically significant differences in the prevalence of $+276 \mathrm{G}>\mathrm{T}$ ADIPOQ polymorphism were found between the phenotypes [11], as in our study. In addition, they found more carriers of the +45T ADIPOQ allele among the MUH subjects with abdominal obesity than in the MH subjects. Also, the TT genotype was associated with higher odds of metabolic disorders in subjects with abdominal obesity (OR 2.331, 95\% CI 1.121-5.132, $p=$ 0.042 ) [11]. These results are in accordance with the outcome of our study, where subjects with NW and the GG or TG genotype presented significantly lower odds of the MUH phenotype. We also analyzed relationships between polymorphisms and metabolic alterations used to classify $\mathrm{MH}$ and MUH subjects to see which determining features of the MUH phenotype the SNPs are influencing, and it was found that $\mathrm{SNP}+45 \mathrm{~T}>\mathrm{G}$ was associated with hypertriglyceridemia, which is in the same direction of the altered metabolic state observed in MUH subjects; besides, hypertriglyceridemia is often involved in the development of insulin resistance, $\mathrm{T} 2 \mathrm{D}$, and cardiovascular disease [34]. This polymorphism has been poorly explored with regard to its relation to serum triglyceride 
levels, with controversial results [35, 36], and to our knowledge no study has reported this association in a Mexican-Mestizo population.

Regarding the $-11391 \mathrm{G}>\mathrm{A}$ and $-11377 \mathrm{C}>\mathrm{G}$ ADIPOQ polymorphisms, subjects with two copies of the GG haplotype had lower adiponectin levels than those with no copies. In fact, two similar haplotype studies of these genetic variations were carried out on European populations. In one of them, GG was considered as the "at-risk" haplotype due to the hypoadiponectinemia found in French subjects with T2D [18]. In the second study on a German population at risk of T2D it was reported that altered plasma adiponectin levels were indeed related to progression of the disease, as well as to this haplotype. Remarkably, the latter report focused on the "protective" role of the AC haplotype, rather than on the GG haplotype as a risk factor [37]. Although many studies focus on "protective" connotations of genotypes or haplotypes with positive effects on health, we are inclined to interpret this type of outcome as "risk-lowering," since this promotes a more cautious statement when it comes to gene-environment interactions. This scientific evidence supports the key role that these haplotypes play in the risk of developing metabolic alterations along with marked changes in adiponectin blood levels. Interestingly, we also found that carriers of the CC genotype at the $-11377 \mathrm{C}>\mathrm{G}$ SNP showed higher adiponectin serum levels than subjects with one or two polymorphic alleles. These findings are in accordance with a study on a Danish population, where carriers of the CC genotype displayed significantly higher adiponectin levels in plasma than CG or GG carriers. As a matter of fact, they also found supporting evidence that carrying the GG genotype for either the $-11391 \mathrm{G}>\mathrm{A}$ or the $-11377 \mathrm{C}>\mathrm{G} A D I$ $P O Q$ SNP is a predisposing risk factor for hypoadiponectinemia [38].

In summary, there were no differences in frequencies between ADIPOQ genetic variants and phenotypes; however, SNP $-11377 \mathrm{C}>\mathrm{G}$ and carriers of two copies of the GGhaplotype of ADIPOQ $(-11391 \mathrm{G}>\mathrm{A}$ and $-11377 \mathrm{C}>\mathrm{G})$ displayed lower serum adiponectin concentrations in the entire population. Despite these results, EW-MUH subjects had lower HMW adiponectin concentrations, possibly because MUH subjects who have a higher amount of adipose tissue have dysfunctional adipocytes, which leads to lowered secretion of adiponectin into the bloodstream, as reported in experimental models [15]. In addition, the protective association of the TG and GG genotypes of SNP $+45 \mathrm{~T}>\mathrm{G}$ was lost in subjects with EW, which suggests that more adipose tissue, or other envi- ronmental factors such as less physical activity and an imbalanced diet, could have a major influence on susceptibility to an MUH phenotype [39]. To our knowledge, this is the first time that these genetic variants have been analyzed in $\mathrm{MH}$ and MUH phenotypes in a MexicanMestizo population; therefore, more studies are needed on Mestizos and other ethnicities that support our results and conclusions.

The limitations of this study include its sample size and transversal design. However, the results observed could be a precedent for other studies with larger populations. Due to the study design, it was not possible to determine whether lower adiponectin levels precede the MUH phenotype or vice versa; therefore, longitudinal or intervention studies are needed to clarify this finding. In addition, we did not evaluate the physical activity level, which has been considered as a potential factor affecting the metabolic profile and adiponectin levels [12, 40]. Therefore, physical activity should be considered in future research, since it could be a determining factor for the presence of the $\mathrm{MH}$ phenotype.

\section{Acknowledgements}

The authors cordially thank the University of Guadalajara and the subjects who participated in this study. All figures were created with BioRender.

\section{Statement of Ethics}

This study was approved by the Human Research Ethics Committee of the University of Guadalajara (registration No. CI/019/2010). The study was conducted at the "Fray Antonio Alcalde" Civil Hospital of Guadalajara, Jalisco, Mexico. All procedures were carried out in accordance with the guidelines for human studies and with the World Medical Association Declaration of Helsinki. All subjects gave their written informed consent signature.

\section{Conflict of Interest Statement}

The authors have no conflicts of interest to declare.

\section{Funding Sources}

This work was supported by the Fondo de Desarrollo Científico de Jalisco FODECIJAL (8146-2019).
Metabolically Unhealthy Phenotype,

Adiponectin, and Gene Variants
Lifestyle Genomics 2020;13:172-179

DOI: $10.1159 / 000510021$ 


\section{Author Contributions}

N.T.-C.: conception, methodology design, conceptualization, statistical analysis, and writing and drafting of the work; final approval and agreement on accuracy. W.C.-P.: design, statistical analysis, interpretation of data, and writing and critical revision of the content; final approval and agreement on accuracy. R.R.-E.: interpretation of data, writing, and drafting; final approval and agreement on accuracy. S.C.R.-R.: writing and drafting of the work; final approval and agreement on accuracy. E.M.-L.: interpretation and acquisition of data, conception, and critical revision; final approval and agreement on accuracy.

\section{References}

1 Scherer PE. Adipose tissue: from lipid storage compartment to endocrine organ. Diabetes. 2006 Jun;55(6):1537-45.

2 Kahn SE, Hull RL, Utzschneider KM. Mechanisms linking obesity to insulin resistance and type 2 diabetes. Nature. 2006 Dec;444(7121): $840-6$.

3 Cheng KK, Lam KS, Wang B, Xu A. Signaling mechanisms underlying the insulin-sensitizing effects of adiponectin. Best Pract Res Clin Endocrinol Metab. 2014 Jan;28(1):3-13.

4 Riestra P, Gebreab SY, Xu R, Khan RJ, Bidulescu A, Correa A, et al. Gender-specific associations between ADIPOQ gene polymorphisms and adiponectin levels and obesity in the Jackson Heart Study cohort. BMC Med Genet. 2015 Aug;16(1):65.

5 Ahima RS. Metabolic actions of adipocyte hormones: focus on adiponectin. Obesity (Silver Spring). 2006 Feb;14(Suppl 1):9S-15S.

6 Moreno-Indias I, Oliva-Olivera W, Omiste A, Castellano-Castillo D, Lhamyani S, Camargo $\mathrm{A}$, et al. Adipose tissue infiltration in normalweight subjects and its impact on metabolic function. Transl Res. 2016 Jun;172:6-17.e3.

7 Longo M, Zatterale F, Naderi J, Parrillo L, Formisano P, Raciti GA, et al. Adipose Tissue Dysfunction as Determinant of Obesity-Associated Metabolic Complications. Int J Mol Sci. 2019 May;20(9):E2358.

8 Jo J, Gavrilova O, Pack S, Jou W, Mullen S, Sumner AE, et al. Hypertrophy and/or Hyperplasia: Dynamics of Adipose Tissue Growth. PLoS Comput Biol. 2009 Mar; 5(3):e1000324.

9 Karelis AD, Faraj M, Bastard JP, St-Pierre DH, Brochu M, Prud'homme D, et al. The metabolically healthy but obese individual presents a favorable inflammation profile. J Clin Endocrinol Metab. 2005 Jul;90(7):414550.

10 De Lorenzo A, Soldati L, Sarlo F, Calvani M, Di Lorenzo N, Di Renzo L. New obesity classification criteria as a tool for bariatric surgery indication. World J Gastroenterol. 2016 Jan; 22(2):681-703.

11 Berezina A, Belyaeva O, Berkovich O, Baranova E, Karonova $\mathrm{T}$, Bazhenova E, et al. Prevalence, Risk Factors, and Genetic Traits in Metabolically Healthy and Unhealthy Obese Individuals. Biomed Res Int. 2015; 2015:548734.
12 Torres-Castillo N, Campos-Perez W, Gonzalez-Becerra K, Hernandez-Cañaveral I, Vizmanos B, Muñoz-Valle J, et al. Waist Circumference Is an Anthropometric Parameter That Identifies Women with Metabolically Unhealthy Phenotypes. Nutrients. 2018 Apr; 10(4):447.

13 Qi L, Li T, Rimm E, Zhang C, Rifai N, Hunter $\mathrm{D}$, et al. The +276 polymorphism of the APM1 gene, plasma adiponectin concentration, and cardiovascular risk in diabetic men. Diabetes. 2005 May;54(5):1607-10.

14 Kern PA, Di Gregorio GB, Lu T, Rassouli N, Ranganathan G. Adiponectin expression from human adipose tissue: relation to obesity, insulin resistance, and tumor necrosis factor-alpha expression. Diabetes. 2003 Jul; 52(7):1779-85.

15 Torre-Villalvazo I, Bunt AE, Alemán G, Marquez-Mota CC, Diaz-Villaseñor A, Noriega LG, et al. Adiponectin synthesis and secretion by subcutaneous adipose tissue is impaired during obesity by endoplasmic reticulum stress. J Cell Biochem. 2018 Jul;119(7):597084.

16 Chang CS, Lu YJ, Chang HH, Hsu SH, Kuo $\mathrm{PH}$, Shieh CC, et al. Role of adiponectin gene variants, adipokines and hydrometry-based percent body fat in metabolically healthy and abnormal obesity. Obes Res Clin Pract. 2018 Jan-Feb;12(Suppl 2):49-61.

17 Mackevics V, Heid IM, Wagner SA, Cip P, Doppelmayr H, Lejnieks A, et al. The adiponectin gene is associated with adiponectin levels but not with characteristics of the insulin resistance syndrome in healthy Caucasians. Eur J Hum Genet. 2006 Mar; 14(3):34956.

18 Vasseur F, Helbecque N, Dina C, Lobbens S, Delannoy V, Gaget S, et al. Single-nucleotide polymorphism haplotypes in the both proximal promoter and exon 3 of the APM1 gene modulate adipocyte-secreted adiponectin hormone levels and contribute to the genetic risk for type 2 diabetes in French Caucasians. Hum Mol Genet. 2002 Oct;11(21):2607-14.

19 Taghadomi Masoumi Z, Eshraghian MR, Hedayati M, Pishva H. Association between uncoupling protein 2, adiponectin and resting energy expenditure in obese women with nor$\mathrm{mal}$ and low resting energy expenditure. Gynecol Endocrinol. 2018 Feb;34(2):166-70.
20 Campos-Perez W, Torres-Castillo N, PerezRobles M, Muñoz-Valle JF, Vizmanos-Lamotte B, Martinez-Lopez E. Interaction of Vitamin E Intake and Pro12Ala Polymorphism of PPARG with Adiponectin Levels. J Nutrigenet Nutrigenomics. 2017;10(5-6):172-80.

21 Landrier JF, Gouranton E, El Yazidi C, Malezet C, Balaguer P, Borel P, et al. Adiponectin expression is induced by vitamin $\mathrm{E}$ via a peroxisome proliferator-activated receptor gamma-dependent mechanism. Endocrinology. 2009 Dec;150(12):5318-25.

22 Iwaki M, Matsuda M, Maeda N, Funahashi T, Matsuzawa Y, Makishima M, et al. Induction of adiponectin, a fat-derived antidiabetic and antiatherogenic factor, by nuclear receptors. Diabetes. 2003 Jul;52(7):1655-63.

23 World Medical Association. World Medical Association Declaration of Helsinki: ethical principles for medical research involving human subjects. JAMA. 2013 Nov;310(20): 2191-4.

24 Boonchaya-anant P, Apovian CM. Metabolically healthy obesity - does it exist? Curr Atheroscler Rep. 2014 Oct;16(10):441.

25 Primeau V, Coderre L, Karelis AD, Brochu M, Lavoie ME, Messier V, et al. Characterizing the profile of obese patients who are metabolically healthy. Int J Obes. 2011 Jul;35(7):97181.

26 Aguilar-Salinas CA, García EG, Robles L, Riaño D, Ruiz-Gomez DG, García-Ulloa AC, et al. High adiponectin concentrations are associated with the metabolically healthy obese phenotype. J Clin Endocrinol Metab. 2008 Oct;93(10):4075-9.

27 Alberti KG, Eckel RH, Grundy SM, Zimmet PZ, Cleeman JI, Donato KA, et al.; International Diabetes Federation Task Force on Epidemiology and Prevention; National Heart, Lung, and Blood Institute; American Heart Association; World Heart Federation; International Atherosclerosis Society; International Association for the Study of Obesity. Harmonizing the metabolic syndrome: a joint interim statement of the International Diabetes Federation Task Force on Epidemiology and Prevention; National Heart, Lung, and Blood Institute; American Heart Association; World Heart Federation; International Atherosclerosis Society; and International Association for the Study of Obesity. Circulation. 2009 Oct;120(16):1640-5. 
28 Matthews DR, Hosker JP, Rudenski AS, Naylor BA, Treacher DF, Turner RC. Homeostasis model assessment: insulin resistance and beta-cell function from fasting plasma glucose and insulin concentrations in man. Diabetologia. $1985 \mathrm{Jul} ; 28(7): 412-9$.

29 Zhu N, Pankow JS, Ballantyne CM, Couper D, Hoogeveen RC, Pereira M, et al. High-molecular-weight adiponectin and the risk of type 2 diabetes in the ARIC study. J Clin Endocrinol Metab. 2010 Nov;95(11):5097-104.

30 Miller SA, Dykes DD, Polesky HF. A simple salting out procedure for extracting DNA from human nucleated cells. Nucleic Acids Res. 1988 Feb;16(3):1215.

31 Elisha B, Karelis AD, Imbeault P, RabasaLhoret R. Effects of acute hyperinsulinaemia on total and high-molecular-weight adiponectin concentration in metabolically healthy but obese postmenopausal women: a Montreal-Ottawa New Emerging Team (MONET) study. Diabetes Metab. 2010 Sep;36(4):31921.

32 Fulcher J, O’Connell R, Voysey M, Emberson J, Blackwell L, Mihaylova B, et al.; Cholesterol
Treatment Trialists' (CTT) Collaboration. Efficacy and safety of LDL-lowering therapy among men and women: meta-analysis of individual data from 174,000 participants in 27 randomised trials. Lancet. 2015 Apr; 385(9976):1397-405

33 World Health Organization. Obesity and overweight [accessed 2018 Jul 11]. 2018. Available from: https://www.who.int/news-room/factsheets/detail/obesity-and-overweight.

34 Yuan G, Al-Shali KZ, Hegele RA. Hypertriglyceridemia: its etiology, effects and treatment. CMAJ. 2007 Apr;176(8):1113-20.

35 Melistas L, Mantzoros CS, Kontogianni M, Antonopoulou S, Ordovas JM, Yiannakouris $\mathrm{N}$. Association of the $+45 \mathrm{~T}[\{\mathrm{GT}\}] \mathrm{G}$ and $+276 \mathrm{G}[\{\mathrm{GT}\}] \mathrm{T}$ polymorphisms in the adiponectin gene with insulin resistance in nondiabetic Greek women. Eur J Endocrinol. 2009 Dec;161(6):845-52.

36 Lee JY, Cho JK, Hong HR, Jin YY, Kang HS Genetic effects of adiponectin single nucleotide polymorphisms on the clustering of metabolic risk factors in young Korean adults. Eur J Appl Physiol. 2012 Feb;112(2):623-9.
37 Schwarz PE, Towers GW, Fischer S, Govindarajalu S, Schulze J, Bornstein SR, et al. Hypoadiponectinemia is associated with progression toward type 2 diabetes and genetic variation in the ADIPOQ gene promoter. Diabetes Care. 2006 Jul;29(7):1645-50.

38 Tankó LB, Siddiq A, Lecoeur C, Larsen PJ, Christiansen C, Walley A, et al. ACDC/adiponectin and PPAR- $\gamma$ gene polymorphisms: implications for features of obesity. Obes Res. 2005 Dec;13(12):2113-21.

39 Ramos-Lopez O, Riezu-Boj JI, Milagro FI, Cuervo M, Goni L, Martinez JA. Genetic and nongenetic factors explaining metabolically healthy and unhealthy phenotypes in participants with excessive adiposity: relevance for personalized nutrition. Ther Adv Endocrinol Metab. 2019;10:2042018819877303.

40 Campos-Pérez W, González-Becerra K, Ramos-López O, Silva-Gómez JA, Barrón-Cabrera E, Roman S, et al. Same Dietary but Different Physical Activity Pattern in Normal-Weight and Overweight Mexican Subjects. J Food Nutr Res. 2016 Nov;4(11):72935. 